\title{
COUGH
}

\section{Cough suppression during flexible bronchoscopy using combined sedation with midazolam and hydrocodone: a randomised, double blind, placebo controlled trial}

\author{
D Stolz, P N Chhajed, J D Leuppi, M Brutsche, E Pflimlin, M Tamm
}

Thorax 2004;59:773-776. doi: 10.1136/thx.2003.019836

See end of article for authors' affiliations

Correspondence to: Dr D Stolz, Division of Respiratory Medicine and Pulmonary Cell Research, University Hospital Basel, Petersgraben 4, $\mathrm{CH}-4031$, Basel, Switzerland; daistolz@yahoo.com

Received 5December 2003 Accepted 5 May 2004

\begin{abstract}
Background: Current British Thoracic Society guidelines do not recommend routinely the combined use of a benzodiazepine and opiate during flexible bronchoscopy (FB). A randomised, placebo controlled, double blind study was undertaken to determine whether hydrocodone in combination with midazolan improves cough suppression during FB without increasing the risk of desaturation.

Methods: 120 patients were randomised to receive midazolam and $5 \mathrm{mg}$ IV hydrocodone or midazolam and placebo with topical anaesthesia. Pulse oximetry was recorded continuously during FB. Bronchoscopists and nurses charted their perception of cough and the patients rated their discomfort during the procedure on a $10 \mathrm{~cm}$ visual analogue scale (VAS).

Results: There was no significant difference between the two groups with regard to the indication for $F B$, duration of procedure (21 (11) $\mathrm{min} v 22(10) \mathrm{min}, \mathrm{p}=0.570)$, doses of supplemental lignocaine (171 (60) $\mathrm{mg} v 173(66) \mathrm{mg}, \mathrm{p}=0.766)$ and midazolam (4.5 (2.3) mg v $4.9(2.7) \mathrm{mg}, \mathrm{p}=0.309)$, lowest oxygen saturation ( $94.8(2.7) \vee 94.9(2.7), p=0.433)$, and desaturations $\leqslant 90 \%$. Perception of cough by both the bronchoscopist and the nurse was significantly lower in the hydrocodone group (3 (0-10) and $3(0-10))$ than in the placebo group $(6(0-10)$ and $6(0-10))$, respectively $(p=0.001)$. According to the VAS scale, patients' tolerance was also significantly better with hydrocodone than with placebo $(2(0-8) \mathrm{v}$ $3(0-9), p=0.043)$.

Conclusion: The combination of midazolam and hydrocodone markedly reduces cough during FB without causing significant desaturation, especially when invasive diagnostic procedures are performed.
\end{abstract}

$\mathrm{T}$ he ideal premedication for diagnostic flexible bronchoscopy (FB) is still to be defined. ${ }^{1}$ Current British Thoracic Society (BTS) guidelines suggest that sedation in incremental doses should be offered to all patients undergoing diagnostic FB, except where there are contraindications. ${ }^{12}$ Indeed, sedation has been shown to improve patients' comfort, particularly by reducing pain and providing amnesia to the procedure. ${ }^{3-5}$ Combined sedation with a benzodiazepine and an opiate allows a reduction in the dose of supplemental local anaesthesia. Furthermore, it probably provides a better antitussive effect than a benzodiazepine alone. ${ }^{6-9}$ Such a combination continues to be used, especially if the physician is concerned about cough, despite the fact that there is no such recommendation in the BTS guidelines. ${ }^{12}{ }^{10}$ Arguments against this combination cite more common oxygen desaturation and carbon dioxide retention than with a benzodiazepine alone. ${ }^{2610}$ However, the evidence supporting this argument is fairly limited. We therefore performed a prospective, randomised, placebo controlled, double blind study to assess the effect and safety of hydrocodone administration in addition to midazolam during FB.

\section{METHODS}

\section{Patients}

One hundred and twenty consecutive patients undergoing diagnostic FB were prospectively randomised to receive either midazolam and hydrocodone or midazolam and placebo in a double blind fashion. Intubated patients were excluded from the study. Indications for bronchoscopy included suspicion/ staging of bronchogenic neoplasm $(n=46)$, interstitial lung disease $(n=20)$, infection $(n=21)$, palliation $(n=25)$, and miscellaneous $(n=8)$. Transnasal FB was performed in the semi-recumbent position.

\section{Anaesthesia}

Topical anaesthesia was achieved with nebulised 4\% lignocaine solution $(4 \mathrm{ml})$, spraying $2 \%$ lignocaine in the nasopharynx (4 times) and oropharynx (3 times) and instillation of $3 \mathrm{ml} 1 \%$ lignocaine over the vocal cords. In addition, $3 \mathrm{ml}$ aliquots of $1 \%$ lignocaine were instilled in the tracheal bronchial tree by the "spray as you go" technique. The dose of supplemental local anaesthesia given was recorded for each patient.

\section{Study design}

Pulse oximetry was recorded continuously during the procedure and automated non-invasive blood pressure was monitored every 5 minutes. All patients received supplemental oxygen at $4 \mathrm{l} / \mathrm{min}$ via nasal cannula which was increased to $6 \mathrm{l} / \mathrm{min}$ if required to maintain oxygen saturation above $90 \%$.

Immediately before $\mathrm{FB}$ patients were given either $5 \mathrm{mg}$ intravenous hydrocodone or intravenous normal saline as placebo. Conscious sedation was achieved initially with $2 \mathrm{mg}$ midazolam followed by a further $1-2 \mathrm{mg}$ intravenous midazolam boluses which were administered during the procedure at the endoscopist's discretion. Bronchoalveolar lavage (BAL), endobronchial and transbronchial biopsies (TBB), and transbronchial needle aspiration (TBNA) of the mediastinal lymph nodes were performed, depending on the clinical setting.

The duration and type of diagnostic procedures were documented for each patient at the end of FB. The bronchoscopist and the nursing staff independently charted their perception of cough during the procedure on a $10 \mathrm{~cm}$ visual analogue scale (VAS) where 0 represented no cough and 10 represented incessant cough. Two hours after the 
Table 1 Patient characteristics and bronchoscopic procedures in the two study groups

\begin{tabular}{|c|c|c|c|}
\hline & $\begin{array}{l}\text { Hydrocodone } \\
(n=60)\end{array}$ & $\begin{array}{l}\text { Placebo } \\
(n=60)\end{array}$ & $p$ value \\
\hline Male/female & $41 / 19$ & $41 / 19$ & - \\
\hline Mean (SD) age (years) & $62(10)$ & $62(10)$ & - \\
\hline \multicolumn{4}{|l|}{ Overall procedures } \\
\hline BAL & $28(46 \%)$ & $21(35 \%)$ & 0.265 \\
\hline $\mathrm{BB}$ & 10 (16\%) & $8(13 \%)$ & 0.799 \\
\hline EBB & 14 (23\%) & $18(30 \%)$ & 0.419 \\
\hline TBB & $14(24 \%)$ & $6(10 \%)$ & 0.085 \\
\hline TBNA & $15(25 \%)$ & $9(15 \%)$ & 0.254 \\
\hline \multicolumn{4}{|l|}{ Single procedures } \\
\hline Inspection + BS & $13(22 \%)$ & $15(25 \%)$ & 0.674 \\
\hline BAL & $12(20 \%)$ & $8(13 \%)$ & 0.342 \\
\hline $\mathrm{BB}$ & 0 & 0 & - \\
\hline EBB & $1(2 \%)$ & $1(2 \%)$ & - \\
\hline TBB & 0 & 0 & - \\
\hline TBNA & 0 & 0 & - \\
\hline \multicolumn{4}{|l|}{ Combined procedures } \\
\hline $\mathrm{BAL}+\mathrm{BB}$ & $2(3 \%)$ & $4(7 \%)$ & 0.679 \\
\hline $\mathrm{BAL}+\mathrm{EBB}$ & $8(13 \%)$ & $2(3 \%)$ & 0.095 \\
\hline$B A L+T B B$ & $6(10 \%)$ & $2(3 \%)$ & 0.272 \\
\hline $\mathrm{BAL}+\mathrm{TBNA}$ & $4(7 \%)$ & $2(3 \%)$ & 0.679 \\
\hline$B A L+T B B+T B N A$ & $1(2 \%)$ & 0 & 1 \\
\hline$B B+E B B$ & $1(2 \%)$ & 0 & 1 \\
\hline$B B+T B B$ & $3(5 \%)$ & $1(2 \%)$ & 0.619 \\
\hline$B B+T B N A$ & $7(12 \%)$ & $2(3 \%)$ & 0.163 \\
\hline$E B B+T B B$ & 2 & $1(5 \%)$ & 1 \\
\hline$E B B+T B N A$ & $4(7 \%)$ & $3(5 \%)$ & 1 \\
\hline $\mathrm{TBB}+\mathrm{TBNA}$ & $6(10 \%)$ & $2(3 \%)$ & 0.272 \\
\hline
\end{tabular}

procedure the patients were asked to record their tolerability of the procedure on a $10 \mathrm{~cm}$ VAS. A higher score indicated greater levels of discomfort during the procedure.

\section{Analysis of data}

The two tailed Fisher's exact test was used to compare the distribution of diagnostic procedures in the placebo and hydrocodone groups and the Mann-Whitney test was used to calculate the level of significance between two mean values in the two groups. The Wilcoxon test was used to determine the difference in cough perception between physicians and nurses. Correlation between the judgement of physicians and nurses was further compared using linear regression. Data were analysed using the exact non-parametric test as appropriate, as implemented in the SPSS program (Version 11.5 for Windows ). A p value of $<0.05$ was considered to be statistically significant. The VAS data are presented as median (range).

\section{Sample size}

In a previous study comparing a benzodiazepine alone with a benzodiazepine and an opioid during $\mathrm{FB}$, the mean (SD) cough scores were 2.45 (1.67) and 1.42 (1.67), respectively. ${ }^{6}$ Thus, for the purposes of our study, 57 patients would be needed in each arm to achieve a significance level of $<0.05$ with a power of 0.9 .

\section{RESULTS}

There were no significant differences between the hydrocodone and placebo groups in age, sex, and indication for FB. Bronchoscopic diagnostic procedures were uniformly distributed in both groups (table 1).

The mean lowest $\mathrm{SaO}_{2}$ under supplemental oxygen was similar in both groups. Four patients had an oxygen saturation below 90\% during FB (Pneumocystis carinii pneumonia, methotrexate pneumonitis, metastatic renal and bronchogenic carcinoma).

The duration of the procedure and supplemental lignocaine and midazolam doses used were similar in the hydrocodone

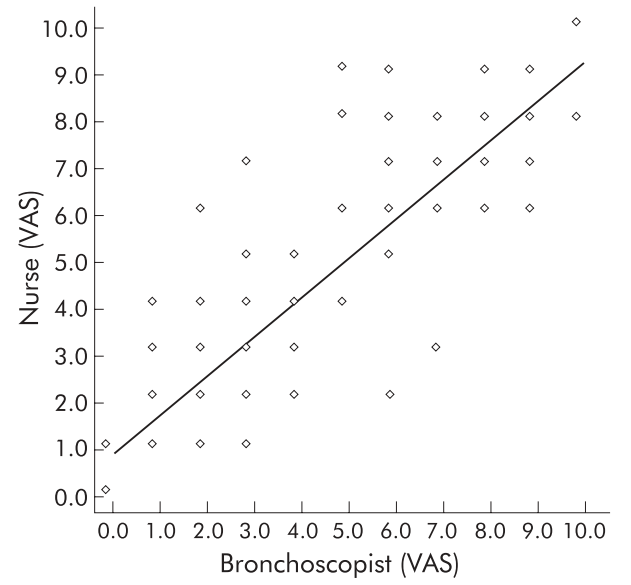

Figure 1 Comparison between cough perception of the bronchoscopist and nursing staff. Data are shown as visual analogue scale (VAS) scores. Linear regression $=0.78$.

and placebo groups. The perception of cough by both the bronchoscopist and the nursing staff was significantly lower in the hydrocodone group $(\mathrm{p}=0.001$ and $\mathrm{p}=0.009$, respectively). There was no difference between the judgement of the physicians and nurses for each patient $(p=0.158$, fig 1$)$. The patients' tolerance to the procedure was also significantly better when they received hydrocodone $(p=0.043$, table 2$)$.

The mean (SD) duration of the procedure in the subgroup of patients undergoing TBB and/or TBNA $(\mathrm{n}=36)$ was 28.9 (9.4) min compared with $19.4(10.5) \min (p=0.001)$ in the remaining patients $(n=84)$. In this subgroup (TBB and/or TBNA), patients who received hydrocodone required less midazolam (3.9 (2.2) $\mathrm{mg}$ ) than those who received placebo (6.9 (3.5) mg; $p=0.006$ ). There was also a trend for the supplemental lignocaine requirement to be less in the hydrocodone group (185 (58) $\mathrm{mg}$ ) than in the placebo group (231 (83) mg; $\mathrm{p}=0.100$ ). The median (range) cough scores 
Table 2 Comparison of the two groups with regard to cough perception, duration of procedure, sedation, and oxygen saturation

\begin{tabular}{|c|c|c|c|}
\hline & $\begin{array}{l}\text { Hydrocodone } \\
(n=60)\end{array}$ & $\begin{array}{l}\text { Placebo } \\
(n=60)\end{array}$ & $\mathrm{p}$ value \\
\hline \multicolumn{4}{|l|}{ Cough* } \\
\hline Bronchoscopist (VAS) & $3(0-10)$ & $6(0-10)$ & 0.001 \\
\hline Nursing team (VAS) & $3(0-10)$ & $6(0-10)$ & 0.009 \\
\hline Patient discomfort (VAS) & $2(0-8)$ & $3(0-9)$ & 0.043 \\
\hline Duration of procedure $(\mathrm{min}) \dagger \ddagger$ & $21(11), 2-45$ & $22(10), 5-60$ & 0.570 \\
\hline Lignocaine dose (mg)† & $171(60), 60-330$ & $173(66), 90-450$ & 0.766 \\
\hline Midazolam dose $(\mathrm{mg}) \dagger$ & $4.5(2.3), 2-10$ & $4.9(2.7), 3-15$ & 0.309 \\
\hline Mean lowest $\mathrm{SaO}_{2}$ & $94.8(2.7)$ & $94.9(2.7)$ & 0.433 \\
\hline \multicolumn{4}{|c|}{$\begin{array}{l}\text { VAS = visual analogue scale. } \\
{ }^{*} \text { Median (range). } \\
\text { †Mean (SD), range. } \\
\text { tFrom insertion of bronchoscope to removal. } \\
\text { - } \mathrm{SaO}_{2} \text { measured on } 4-6 \text { litres oxygen. }\end{array}$} \\
\hline
\end{tabular}

in the hydrocodone and placebo groups were $3(0-9)$ and 8 (3-9), respectively $(p<0.001)$ as perceived by the physician and $3.5(0-8)$ and $7(4-9)$, respectively $(p=0.001)$ as perceived by the nursing staff.

\section{DISCUSSION}

Almost 95\% of flexible bronchoscopic examinations are now carried out under sedation assisted local anaesthesia. ${ }^{12}$ Agitation caused by inadequate sedation and excessive cough may lead to hypoxemia during FB. ${ }^{511}$ Proper sedation improves the patient's tolerance during FB and allows the bronchoscopist to perform invasive procedures.

Midazolam has become the drug of choice among the benzodiazepines and is used in up to $85 \%$ of cases because of its short half life and rapid onset of action. ${ }^{2}{ }^{12}$ Benzodiazepines provide only sedation and amnesia and have no antitussive effects so they are often used in conjunction with opiates. ${ }^{6-8}$ The primary action of the currently available opioids is on the central cough pathway. The opioid receptor subtypes are $\mu, \kappa$ and $\delta .{ }^{13}$ The antitussive effect is mediated predominantly by $\mu$ receptors with a possible role for $\kappa$ receptors. ${ }^{14}$

Hydrocodone is a codeine derivative with a similar molecular structure to hydromorphone, which has been widely used for cough treatment since $1923 .{ }^{15}{ }^{16}$ It is assumed to have a greater antitussive activity than codeine but less than morphine. ${ }^{17}$ Hydrocodone was effective and tolerable in most previous studies, and superior to codeine in some. ${ }^{16}$ It is considered to be the antitussive agent of choice for chronic use because it seems to have less central nervous system and gastrointestinal side effects than codeine and to be less constipating than morphine. ${ }^{18-20}$ Lately, synthetic shorter acting narcotics such as fentanyl, alfentanil, and nalbuphine have been used during invasive procedures. ${ }^{6-8}$ However, we are not aware of any studies comparing the effects of hydrocodone and the new synthetic agents. Hydrocodone was used in this study as it is 18 times cheaper than alfentanil.

Activation of the cough centre in the brain stem causes the respiratory muscles to induce cough, the bronchial smooth muscle to cause bronchoconstriction, and subsequently the airway submucosal glands to secrete mucus..$^{21}$ The control of coughing is of paramount importance for the quality of a bronchoscopy, as this facilitates ease of viewing the bronchial tree and obtaining good biopsy samples. ${ }^{6}$ Contamination with blood and bronchial secretions due to cough decreases the diagnostic yield of BAL fluid. Moreover, excessive cough can substantially increase the risk of complications or even prevent the performance of invasive procedures during the bronchoscopic examination. Coughing during TBB raises intrathoracic pressure leading to an increased risk of pneumothorax. ${ }^{12}$ Moreover, $25 \%$ of patients consider cough the worst side effect of bronchoscopy, and reduction of cough with an opiate can substantially influence their willingness to repeat the examination. ${ }^{22}$

Greig et $a^{6}$ compared midazolam, alfentanyl, and a combination of the two for sedation during FB. Oxygen saturation fell significantly more in those who received midazolam and alfentanyl than in those who received alfentanyl alone. Although not statistically significant, there was a trend towards more desaturations in the combination group compared with midazolam alone. Contrary to the BTS recommendations, oxygen supplementation was not routinely provided in this study, despite marked desaturation in some patients. Supplemental oxygen is currently given to all patients undergoing FB at most institutions. ${ }^{2} 1023$

Tsunezuka et $a l^{7}$ reported that, under insufficient local anaesthesia and midazolam sedation, codeine phosphate was effective in suppressing cough during $\mathrm{FB}$ and did not cause more oxygen desaturations than placebo. The codeine group had an even higher mean lowest oxygen saturation than the placebo group. This effect was attributed to the suppression of cough which can itself cause oxygen desaturation.

Our randomised, double blind study showed that, if supplemental oxygen is routinely provided during bronchoscopy, the combination of midazolam and hydrocodone does not cause a greater fall in oxygen saturation than midazolam alone. Furthermore, the cough scores perceived by the bronchoscopist and nursing staff and the patient's discomfort were significantly lower in those who received hydrocodone compared with placebo.

One possible limitation of this study is that the patients' tolerability may have been overestimated 2 hours after the procedure because of the amnesic effect of midazolam. However, the clear difference in the discomfort of the patients between the two groups indicates the superiority of combined sedation. Moreover, according to several previous studies, wake up time for combined sedation with an opiate and benzodiazepine is 35-60 minutes and discharge time 75120 minutes after the procedure. ${ }^{6824}$ We therefore believe that it is fair to assume that patients were able to estimate their discomfort during FB 2 hours after the procedure.

Hydrocodone seemed to be particularly beneficial in significantly reducing the dose of sedative as well as the severity of cough in patients undergoing TBB and/or TBNA, despite the fact that the procedure was of a longer duration.

The findings of our study suggest that the benefits of combining a benzodiazepine and an opiate during FB can be effectively achieved with midazolam and hydrocodone. This combination improves operating conditions due to its antitussive effect, provides better patient satisfaction, and is 
safe. We suggest that use of this combination should be adopted as standard sedation for FB in patients without contraindications.

\section{ACKNOWLEDGEMENTS}

The authors thank the endoscopy staff (Esther Gysin, Dusan Jovic, Björn Fehrke, Monika Kohler, Sylvie Groelly, Michael Ortmann, Beatrice Lehner, Catherine Keller, Margot Brenneisen) for their excellent collaboration and Sara Downs PhD for statistical advice.

\section{Authors' affiliations}

D Stolz, P N Chhajed, J D Leuppi, M Brutsche, E Pflimlin, M Tamm, Division of Respiratory Medicine, University Hospital Basel, Basel, Switzerland

\section{REFERENCES}

1 Pickles J, Jeffrey M, Datta A, et al. Is preparation for bronchoscopy optimal? Eur Respir J 2003;22:203-6.

2 British Thoracic Society guidelines on diagnostic flexible bronchoscopy. Thorax 2001;56(Suppl I):i1-21.

3 Gonzalez R, De-La-Rosa-Ramirez I, Maldonado-Hernandez A, et al. Should patients undergoing a bronchoscopy be sedated? Acta Anaesthesiol Scand 2003:47:411-5.

4 Putinati S, Ballerin L, Corbetta L, et al. Patient satisfaction with conscious sedation for bronchoscopy. Chest 1999; 115:1437-40.

5 Matot I, Kramer MR. Sedation in outpatient bronchoscopy. Respir Med 2000;94:1145-53.

6 Greig JH, Cooper SM, Kasimbazi HJ, et al. Sedation for fibre optic bronchoscopy. Respir Med 1995;89:53-6.

7 Tsunezuka Y, Sato H, Tsukioka T, et al. The role of codeine phosphate premedication in fibre-optic bronchoscopy under insufficient local anaesthesia and midazolam sedation. Respir Med 1999;93:413-5.

8 Webb AR, Doherty JF, Chester MR, et al. Sedation for fibreoptic bronchoscopy: comparison of alfentanil with papaveretum and diazepam. Respir Med 1989;83:213-7.
9 Sury MR, Cole PV. Nalbuphine combined with midazolam for outpatient sedation. An assessment in fibreoptic bronchoscopy patients. Anaesthesia 1988;43:285-8.

10 Smyth CM, Stead RJ. Survey of flexible fibreoptic bronchoscopy in the United Kingdom. Eur Respir J 2002;19:458-63.

11 Chhajed PN, Glanville AR. Management of hypoxemia during flexible bronchoscopy. Clin Chest Med 2003;24:511-6.

12 Hattotuwa K, Gamble EA, O'Shaughnessy T, et al. Safety of bronchoscopy, biopsy, and BAL in research patients with COPD. Chest 2002;122:1909-12.

13 Kamei J. Delta-opioid receptor antagonists as a new concept for central acting antitussive drugs. Pulm Pharmacol Ther 2002;15:235-40.

14 Homsi J, Walsh D, Nelson KA. Important drugs for cough in advanced cancer. Support Care Cancer 2001;9:565-74.

15 Homsi J, Walsh D, Nelson KA, et al. Hydrocodone for cough in advanced cancer. Am J Hosp Palliat Care 2000; 17:342-6.

16 Eddy NB, Halbach H, Braenden OJ. Synthetic substances with morphine-like effect: clinical experience; potency, side-effects, addiction liability. Bull WHO 1957; 17:569-863.

17 Braga PC, Allegra L. Centrally acting opioid drugs. New York: Raven Press, 1989.

18 MacEvody GK. Antitussives, expectorants and mucolytic agents. Bethesda, MD: American Society of Health-System Pharmacists, 2000.

19 Turturro MA, Paris PM, Yealy DM, et al. Hydrocodone versus codeine in acute musculoskeletal pain. Ann Emerg Med 1991;20:1100-3.

20 Walsh D, Doona M, Molnar M, et al. Symptom control in advanced cancer: important drugs and routes of administration. Semin Oncol 2000;27:69-83.

21 Irwin RS, Widdicombe J. Cough. In: Murray J, Nadel J, eds. Textbook of respiratory medicine. Philadelphia: Saunders, 1994:529-44.

22 Mendes de Leon C, Bezel R, Karrer W, et al. Premedication in fiber optic bronchoscopy from the patient's and the physician's viewpoint-a randomized study for the comparison of midazolam and hydrocodone. Schweiz Med Wochenschr 1986;116:1267-72.

23 Chhajed PN, Aboyoun C, Malouf MA, et al. Management of acute hypoxemia during flexible bronchoscopy with insertion of a nasopharyngeal tube in lung transplant recipients. Chest 2002;121:1350-4.

24 Bright E, Roseveare C, Dalgleish D, et al. Patient-controlled sedation for colonoscopy: a randomized trial comparing patient-controlled administration of propofol and alfentanil with physician-administered midazolam and pethidine. Endoscopy 2003;35:683-7. 